\title{
Crosstalk between Autophagy and Apoptosis in Intervertebral Disc Degeneration
}

\author{
Bruno Saciloto', Natália Fontana Nicoletti ${ }^{2}$, Manuela Peletti-Figueiró ${ }^{2}{ }^{*}$, Asdrubal Falavigna ${ }^{1,2}$ \\ ${ }^{1}$ Health Sciences Graduate Program, University of Caxias do Sul (UCS), Caxias do Sul, Brazil \\ ${ }^{2}$ Cell Therapy Laboratory (LATEC), University of Caxias do Sul (UCS), Caxias do Sul, Brazil \\ Email: *manu.peletti@gmail.com
}

How to cite this paper: Saciloto, B., Nicoletti, N.F., Peletti-Figueiró, M. and Falavigna, A. (2021) Crosstalk between Autophagy and Apoptosis in Intervertebral Disc Degeneration. Journal of Biosciences and Medicines, 9, 15-29.

https://doi.org/10.4236/jbm.2021.912003

Received: October 26, 2021

Accepted: November 29, 2021

Published: December 2, 2021

Copyright (c) 2021 by author(s) and Scientific Research Publishing Inc. This work is licensed under the Creative Commons Attribution International License (CC BY 4.0).

http://creativecommons.org/licenses/by/4.0/

\begin{abstract}
Objective: To describe the relationship between autophagy and apoptosis and the possible signaling pathways involved in degenerative lumbar intervertebral disc. Summary of Background Data: Autophagy and apoptosis are regulatory cellular mechanisms that determine many pathologies, including degenerative intervertebral disc disease. The interactions between these events in the damage or protection of intervertebral disc cells and in cellular homeostasis remain controversial. Methods: The sample size was twenty patients who underwent lumbar spine surgery for symptomatic disc herniation or spondylolisthesis. Intervertebral discs were classified by magnetic resonance as Pfirrmann grade IV and grade V. Six patients were operated on two levels, resulting in twenty-six intervertebral discs that were submitted to immunohistochemistry to verify the protein expression of autophagy and apoptosis markers. Results: The autophagic markers had greater protein expression in the human intervertebral disc (Pfirrmann Grades IV and V). Under these conditions, autophagy and apoptosis showed a negative correlation. Regarding apoptosis, caspase 8 presented the highest protein expression, which allows inferring the preference for the extrinsic pathway in cell death. Conclusions: Autophagy had the greatest protein expression negative profile compared to apoptosis. Caspase 8 had the highest protein expression in apoptosis.
\end{abstract}

\section{Keywords}

Intervertebral Disc Degeneration, Autophagy, Apoptosis, Crosstalk

\section{Introduction}

Degenerative disc disease (DDD) has been considered the commonest cause of low back pain (LBP) symptoms, with a heavy social and economic burden [1] [2] 
[3]. Clinical and radiological correlation through magnetic resonance imaging (MRI) is essential for proper management, since intervertebral disc (IVD) degeneration is an aging process [4] [5] [6]. External and internal factor associated with DDD are labor-related (i.e. excessive vibration), smoking, aging and genetic predisposition [5] [6] [7].

Apoptosis is programmed cell death responsible for maintaining homeostasis by the induction of death of pathological cells [8]. However, the excess of apoptosis is harmful and can cause DDD [9]. Signaling caspases 8, 9, and effector caspase 3 are the commonest way to detect apoptosis [10]. Apoptosis can occur via two main pathways, extrinsic and intrinsic. Caspase 8 is increased when the extrinsic pathway is activated and caspase 9 when the intrinsic pathway is activated [11] [12]. Even though caspase 8 and 9 act in distinct molecular processes, both activate a proteolytic cascade, which ultimately results in the apoptotic signal [13].

Autophagy is a homeostatic mechanism through which a basal level of autophagy recycles and exchanges the damages organelles, proteins and cytoplasmic components [14] [15]. It functions as an adaptation to stress through delivery of metabolic substrates to cells in an event of energy shortage, providing cell survival and growth [14]. There is progressive breakdown of extracellular matrix (ECM) components as a response to different stimuli such as nutrient deprivation causing excessive autophagy, accumulation of Il- $1 \beta$ and TNF leading to cell death [8] [9] [16] [17]. Autophagy Related Genes ATG types 3, 4 and 7 as well LC3 and SQSTM1 proteins are essential to the autophagic process [18]. In mammalian cells, LC3 is expressed in multiple isoforms: LC3A, LC3B, and LC3C [13] [19]. The increasing levels of LC3A-II versus LC3B-II behave in different ways in different tissues or cell lineages, not defining which is the "best isoform" to be monitored [14]. Even though autophagy acts mainly as a protector of the degenerative state, if excessive it may result in autophagic cell death [16] [17].

IVD preservation is achieved by the cellular balance via autophagy and apoptotic suppression [20] [21]. This study aims to better understand the crosstalk between autophagy and apoptosis and the signaling pathways involved in IVD degeneration.

\section{Patients and Methods}

\subsection{Clinical Statement}

This study was conducted in accordance with ethical standards and approved by the Ethics Committee of the University of Caxias do Sul (CEP/UCS 2.503.156). The patients were invited by an informed consent form.

\subsection{Patient Selection}

The symptomatic patients with spondylolisthesis or lumbar disc herniation were evaluated and treated initially with analgesic and anti-inflammatory medication, epidural infiltration, postural care, motor physical therapy and muscle streng- 
thening. Radiological investigation with lumbar spine X-ray and magnetic resonance imaging (MRI) were performed if the symptoms persisted for two weeks. The surgical indication was determined by pain aggravation and progressive loss of motor function, with a clinical-radiological concordance. The final decision for surgery was made by the patient and their family after explaining the efficacy and risks of surgery, and postoperative care. The patient was invited to enter the study and signed the informed consent form if it was decided to perform surgery.

The Specific Inclusion Criteria for this study were: 1) Patients with degeneration of the lumbar spine IVD diagnosed with clinical-radiological agreement; 2) Refractory to conventional clinical treatment; 3) Patients without satisfactory response to conservative clinical treatment, on average, for two to three months and 4) Patients who signed the informed consent form agreeing with the study. Thus, the Exclusion Criteria were: 1) Clinical-radiological dissociation; 2) Patients on labor compensation; 3) Presence of IVD infection; 4) Previous surgery at the site of the intervertebral disc and 5) Patients who do not sign the consent form agreeing with the research. The selection of patients (inclusion and exclusion criteria) allowed obtaining high reliability in the results and statistical strength in the evaluated data.

\subsection{Radiological and Clinical Evaluation}

The severity of the lumbar spine IVD was determined by magnetic resonance using the Pfirrmann scale [4]. The Pfirrmann scale ranks the severity of IVD from grade I (normal) to grade V (severe degeneration) by acquisition of T2weighted fast average spin-echo images [4].

The clinical evaluation was performed by the Oswestry lumbar functionality (ODI) questionnaire [22]. The scale consists of 10 questions with six alternatives, value ranges from 0 to 5 . The total score is divided by the number of questions answered multiplied by the number 5 and the result of this division is multiplied by 100 . ODI is classified as minimum disability $(0 \%-20 \%)$, moderate disability $(21 \%-40 \%)$, severe disability $(41 \%-60 \%)$, patient who appears invalid $(61 \%-$ $80 \%)$, and bed-restricted individuals (81\% - 100\%) [22].

\subsection{IVD Samples and Tissue Fixation}

The fragments of IVD removed during the surgical procedure were collected and washed twice in sterile vats protected from the light, containing buffered $10 \%$ formalin ( $\mathrm{pH}$ 7.4). This material was transported to the Cell Therapy Laboratory of the University of Caxias do Sul. All samples remained in buffered formalin $10 \%$ (pH 7.4) for $24 \mathrm{~h}$ for complete tissue fixation. After this period, they were catalogued and analyzed macroscopically, where size, coloring, texture and other elements of the piece were evaluated to aid in the study.

\subsection{Hematoxylin and Eosin Staining}

Samples were then dehydrated with consecutive ethyl alcohol 100\% baths, dia- 
phanized in xylol and embedded in paraffin. The blocks containing the selected samples were cut into $3 \mu \mathrm{m}$ sections using Leica microtome RM 2120RT (Leica, Bannockburn, IL, USA).

Hematoxylin and Eosin staining was obtained by standard protocol. Thus, the slides were diaphanized, dehydrated and stained with Harris Hematoxylin solution (WCOR) followed by Eosin (Sigma-Aldrich ${ }^{\circledR}$, Missouri, USA). The final step of the slides was performed with Eukitt ${ }^{\circledR}$ quickhard mounting medium (Fluka Analytical-Thermo Fisher Scientific, Massachusetts, USA).

Images were analyzed using conventional optical microscopy Leica DM2500 (Leica Microsystems, Bannockburn, IL, USA). The images were captured with the LAS V4.4 software microscope (Leica Microsystems, Bannockburn, IL, USA). It should be noted that such basic staining was used only as a way of visual support of the quality of the tissue before the images of immunohistochemistry that were generated, not being part of the analysis and results of the study.

\subsection{Immunohistochemistry}

Immunopositivity for the relation between apoptosis and autophagy expression was assessed on paraffin tissue sections ( $3 \mu \mathrm{m}$ thick) by using polyclonal antibody anti-Caspase 8 (1:1000, Cat. Number PA1-29159, Thermo Fischer Scientific, Massachusetts, EUA), polyclonal antibody anti-Caspase 9 (1:500, Cat Number PA1-29160, Thermo Fischer Scientific, Massachusetts, EUA), polyclonal antibody anti-LC3A/Cleaved (1:10, Cat Number PA5-35196, Thermo Fischer Scientific, Massachusetts, EUA) and polyclonal antibody antiLC3A/LC3B (1:200, Cat Number PA1-16931, Thermo Fischer Scientific, Massachusetts, EUA).

High-temperature antigen retrieval was performed by immersion of the slides into Standard Saline Citrate 2X (3M Sodium Chloride and $0.3 \mathrm{M}$ citric acid, $\mathrm{pH}$ 7) at $98^{\circ} \mathrm{C}-100^{\circ} \mathrm{C}$. The peroxidase was blocked by incubating the sections with $3 \%$ hydrogen peroxide for $20 \mathrm{~min}$. The nonspecific protein binding was blocked with $15 \%$ milk serum solution for $12 \mathrm{~min}$. After incubation at $37^{\circ} \mathrm{C}$ (30 minutes) and room temperature (45 minutes) with primary antibodies, the slides were washed with PBS $1 \mathrm{X}\left(0.8 \% \mathrm{NaCl}, 0.02 \% \mathrm{KCl}, 0.02 \% \mathrm{KH} 2 \mathrm{PO} 4,0.088 \% \mathrm{Na}_{2} \mathrm{HPO}_{4}\right)$ and incubated with the secondary antibody (HiDef Detection Amplifier Mouse \& rabbit, Cell Marque Corporation, Califórnia, EUA) for 12 minutes at room temperature and by detection polymer (HiDef DetectionHRP Polymer Detector, Cell Marque Corporation, Califórnia, EUA) for 12 minutes more at room temperature.

The sections were washed in PBS 1X, and the visualization was completed by using 3,3'-diaminobenzidine (Cell Marque Corporation, Califórnia, EUA) in chromogenic solution and counterstained lightly with Harris's Hematoxylin (WCOR) solution.

Images were examined with a Leica DM2500 optical microscope (Leica Microsystems, Bannockburn, IL, USA) and the images were captured with the LAS V4.4 software microscope (Leica Microsystems, Bannockburn, IL, USA). Five 
images of each sample were captured at 200× magnification [23]. Digitized RGB images were analyzed using Image NIH (National Institute of Health) Image J 1.52a Software (NIH, Bethesda, MD, USA) to quantify the immunopositive Caspase 8, Caspase 9, C3A/Cleaved, LC3A/LC3B. A specific macro was created for each antibody to quantify the immunopositivity of the labeled proteins in the immunohistochemical reactions based on the color of the pixel.

The dark-to-medium brown regions in the sample were selected and used as positive immunolabeling. When necessary, the brightness intensity within ImageJ was used to aid the program analysis. The software generated a macro, which allowed determining the optical density of the positive regions as arbitrary units (AU). All immunohistochemical reactions had the presence of at least one positive control for the primary antibody used (anti-caspase 9, anticaspase 8, cleaved anti-LC3A and anti-LC3A/3B), ensuring the immunohistochemical assay.

\subsection{Statistical Analysis}

Data was stored in the Excel 2007 program. Statistical analysis was performed through the R Project for Statistical Computing 3.6.1 (free software Foundation's GNU General Public License) for FreeBSd and Linux. The evaluation was performed in five images giving greater statistical strength to the tests. All immunohistochemistry data were correlated with radiological and clinical information of patients using the Spearman correlation test and MannWhitney $U$ test with generalized linear model gamma (GLM). Statistical significance was considered when $\mathrm{p}<0.05$.

\section{Results}

Specimens from human intervertebral disc were obtained from 20 patients who were submitted to lumbar surgery for degenerative disc disease (DDD) or lumbar disc herniation. From the entire number of patients, we obtained 26 biological samples of IVD for the study.

\subsection{General Aspects}

A total of 26 samples of human intervertebral discs were obtained from 20 patients, 6 of the patients had removal of 2 IVD discs (Table 1). The sex was equally distributed as male $(n=10)$ and female $(n=10)$. Median age was 49 (range 35 - 72). The mean and standard deviation of the preoperative ODI questionnaire was $65.8 \pm 6.14$ (range 55 - 75) (Table 1).

\subsection{Autophagy Had a Greater Protein Expression}

LC3A had the greatest protein expressed in AU through ImageJ analysis when compared with LC3A/LC3B, Caspase 8 and Caspase 9 (Figure 1). Higher median values related to superior autophagic activity were observed, perhaps associated with the degenerative degree of the samples (Pfirrmann Grades IV and V only). 
Table 1. Clinical-radiological data of the study patients.

\begin{tabular}{|c|c|c|c|c|c|}
\hline & Disc Level & Pfirrmann & Age & Gender & Oswestry \\
\hline $\mathrm{P} 1$ & L4-L5 & 4 & 46 & $\mathrm{~F}$ & 65 \\
\hline \multirow[t]{2}{*}{$\mathrm{P} 2$} & L4-L5 & 4 & 46 & M & 75 \\
\hline & L5-S1 & 5 & & & 75 \\
\hline P3 & L4-L5 & 5 & 68 & $\mathrm{~F}$ & 70 \\
\hline $\mathrm{P} 4$ & L4-L5 & 4 & 46 & $\mathrm{~F}$ & 75 \\
\hline P5 & L4-L5 & 4 & 49 & M & 65 \\
\hline P6 & L4-L5 & 4 & 39 & M & 65 \\
\hline P7 & L5-S1 & 4 & 35 & $\mathrm{~F}$ & 60 \\
\hline \multirow[t]{2}{*}{ P8 } & L3-L4 & 4 & 72 & $\mathrm{~F}$ & 70 \\
\hline & L5-S1 & 5 & & & \\
\hline P9 & L5-S1 & 4 & 51 & M & 60 \\
\hline \multirow[t]{2}{*}{ P10 } & L4-L5 & 5 & 57 & M & 55 \\
\hline & L5-S1 & 4 & & & \\
\hline \multirow[t]{2}{*}{ P11 } & L3-L4 & 5 & 64 & $\mathrm{~F}$ & 65 \\
\hline & L4-L5 & 5 & & & \\
\hline P12 & L5-S1 & 5 & 39 & M & 70 \\
\hline $\mathrm{P} 13$ & L4-L5 & 4 & 66 & $\mathrm{~F}$ & 65 \\
\hline \multirow[t]{2}{*}{ P14 } & L4-L5 & 4 & 43 & F & 70 \\
\hline & L5-S1 & 4 & & & \\
\hline P15 & L4-L5 & 4 & 44 & M & 75 \\
\hline P16 & L5-S1 & 5 & 38 & M & 60 \\
\hline P17 & L4-L5 & 4 & 48 & $\mathrm{~F}$ & 65 \\
\hline P18 & L4-L5 & 4 & 46 & $\mathrm{~F}$ & 55 \\
\hline \multirow[t]{2}{*}{ P19 } & L4-L5 & 4 & 59 & M & 60 \\
\hline & L5-S1 & 5 & & & \\
\hline P20 & L3-L4 & 5 & 71 & M & 70 \\
\hline
\end{tabular}

\subsection{Autophagy versus Apoptosis}

A statistically significant result $(\mathrm{p}<0.001)$ was observed between autophagy markers (LC3A and LC3A/LC3B) and apoptotic ones (caspase 8 and caspase 9).

A negative Rho (-0.58) between the autophagy and apoptosis was observed by Spearman correlation. Autophagy is negatively correlated with apoptosis in DDDPfirrmann Grades IV and V ( $\mathrm{p}<0.001)$.

\subsection{LC3A vs Caspase 8}

GLM analysis showed a positive relation between protein expression of LC3A 


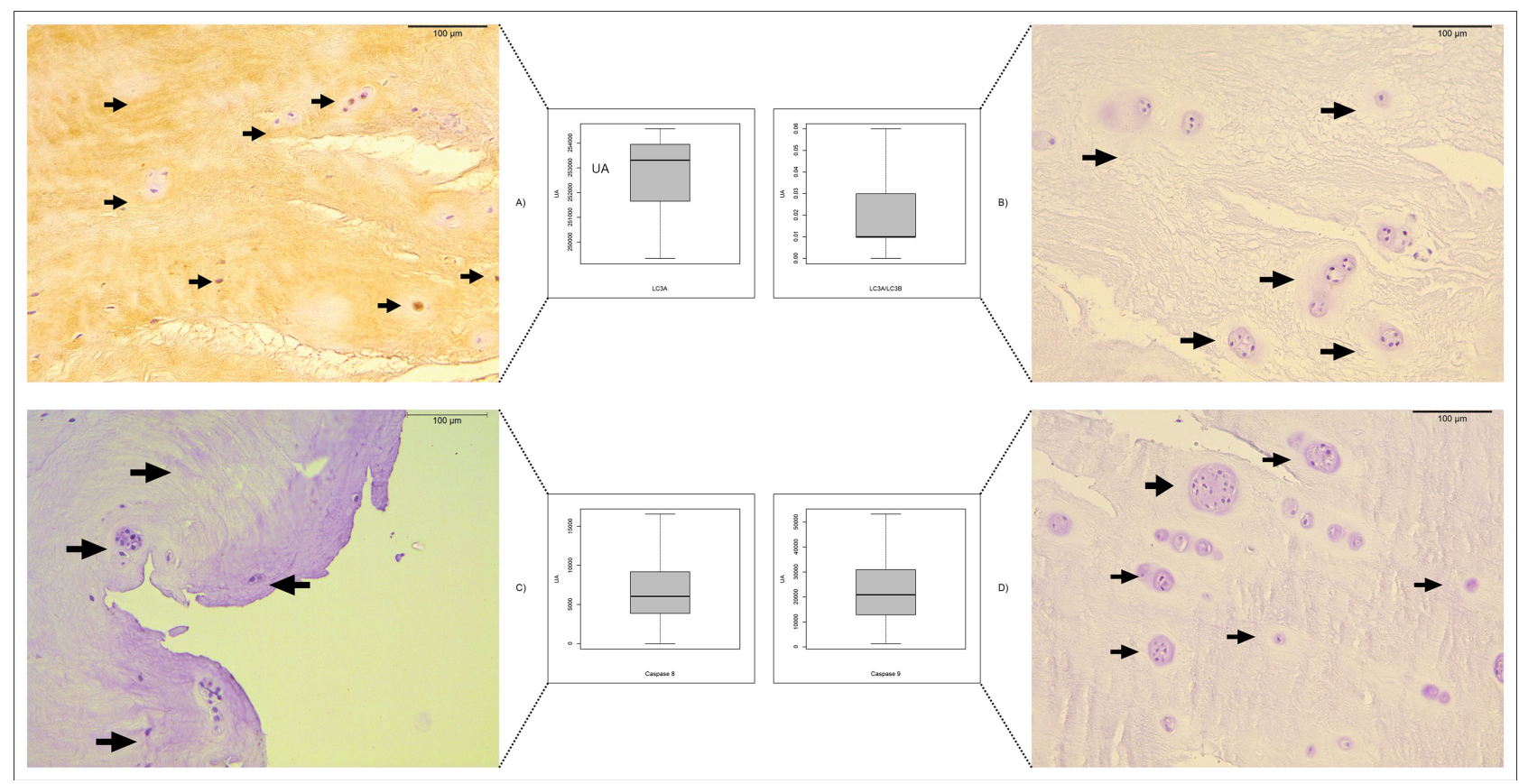

Figure 1. Protein expression in autophagy and apoptosis. Values showed in a boxplot demonstrate the median and interquartile range values and next is the protein expression as visualized in immunohistochemistry (200× magnification). Black arrows mark the protein expression in optical microscopy. Examples of four samples for (A) Antibody anti-LC3A, (B) Antibody anti-LC3A/ LC3B; (C) Antibody anti-caspase 8 and (D) Antibody anti-caspase 9.

and caspase $8(\mathrm{P}<0.002)$, insinuating a prevalence of the extrinsic apoptotic pathway over the intrinsic one.

\subsection{Pfirrmann vs Autophagy and Apoptosis}

The GLM analysis between Pfirrmann grade, autophagy and apoptosis showed a statistical significant $(\mathrm{p}<0.03)$ result only at the variables IVD Grade V and caspase 9.

\section{Discussion}

An inverse correlation was found between autophagy and apoptosis in Pfirrmann Grades IV and V IVDs. As autophagy specific protein expression, we found LC3A predominant. Baseline and response profile expression for both LC3A-II and LC3B-II can assess the autophagic flux [24]. The confocal microscopy with double immunofluorescence showed a lack of autophagosomes LC3A-II and LC3B-II proteins expression [24]. The present study showed an immunohistochemistry marking with a prominent cytoplasmic localization of LC3A and nucleolar region of LC3A/LC3B. A similar finding was observed in another study [24]. Isoform LC3C is poorly or not expressed in most normal tissues [19] [25] [26].

Autophagy has a variety of pathophysiological roles, such as starvation adaptation, intracellular protein and organelle clearance, development, antiaging, elimination of microorganisms, cell death, tumor suppression and antigen presen- 
tation [15]. Autophagy can harm the cells when there is a loss of balance between destruction and construction, with higher levels of destruction [27].

If the PI3K-AKT pathway is induced under stress (Theb-GTP), mTOR is influenced and autophagic flow is inhibited [28]. The stress causes a negative modulation over mTOR resulting in a pro-autophagy phenomenon [28]. When mTOR is suppressed, the ULK complex leads to a Beclin-1 stimulation and subsequently ATG16L, which characterizes the phagophore stage [29]. In conjunction with ATG5 and ATG12, it forms the ATG5-ATG12-ATG16L complex, which will ultimately favor the conversion of cytosolic LC3-I into intra-autophagosomal LC3II through phosphatidylethanolamine (PE), constituting a marker of autophagosome formation and lysosomal activity with higher protein expression of the later.

Hence, with our results trending toward a dominant autophagic phenomenon via LC3A expression, we hypothesize that the constant axial compression and translational movement influenced the IVD degeneration process. The degeneration might act or attenuate the natural apoptotic effect in NP cells, enabling a protective or pro-survival effect of NP cells [30].

Rat NP cells exposed to compression underwent ROS-mediated autophagy, leading to cell degeneration and increased levels of Beclin 1 and processing of LC3B-I to LC3B-II, a marker for autophagosome formation [31]. Appropriate autophagic activity enhances the survival of NP cells under conditions of serum deprivation, whereas excessive autophagy triggers apoptosis of NP cells [32]. In a similar model, protein expression significantly increased in LC3 and Beclin 1 in IVD with exposition to $20 \%$ compression, as well as the ratio of LC3-II to LC3-I, with the autophagy being suppressed under higher (>20\%) mechanical tension as apoptosis progresses [8].

A group of cysteine proteases or caspases are activated via extrinsic or intrinsic signaling pathways when an apoptotic cascade is initiated [11]. Caspase 9 (recruited by APAF-1), resulting from interaction to cytochrome-C, forms the apoptosome and leads to nuclear breakdown through effector caspases [11] [33].

Our results showed that caspase 9 was more active in advanced degenerated discs, Pfirrmann V, hypothesizing that cell degeneration is accompanied by a radiological progression into final deterioration of the disc itself. The intrinsic pathway is regulated by various proteins: $\mathrm{NF}-\mathrm{kB}$ and $\mathrm{Bcl}-2$ protein families [34]. Anti-apoptotic Bcl-2 members repress apoptosis by blocking the release of cytochrome $\mathrm{c}$ whereas the pro-apoptotic members promote apoptosis [35].

A significant inverse correlation between apoptosis and autophagy was observed in the present study. The inverse correlation was mainly represented by antibody anti-LC3A versus protein expression of caspase 8 , showing that an increase in autophagy resulted in suppression of an extrinsic apoptotic pathway. To initiate the extrinsic pathway, also called cytoplasmic, there is an activation of pro-apoptotic receptors such as tumor necrosis factor receptor 1 (TNFR1), death receptors (DRs) and Fas on the cell surface [36]. Death-inducing signaling complex (DISC) is formed with initiator caspase 8 and 10 as procaspases, driving 
their autocatalytic process and releasing into cytoplasm and activating effector caspases [36] [37] [38].

IVD cell senescence is positively related to degree of DDD in adults [39]. After senescence is initiated, it will result in a decrease in the number of viable and functional disc cells because their replication cannot resist disc cell loss caused by apoptosis or cell death [40] (Figure 2).

Furthermore, nutrient deprivation may significantly induce autophagosome formation [41]. Hypoxia also activate autophagy, through hypoxia-inducible-factor (HIF) and downstream TOR inhibition of AMP-activated protein kinase (AMPK) [41]. Since our sample consisted only of Pfirrmann grades IV and V, we assume that a progressive state of DDD was in progress, which corroborated other publications cited above that documented the same predominance of autophagy over apoptosis [8] [30] [31] [41].

Hypoxia and nutrient starvation in IVD cells are common. The cells at the center of the IVD only acquire nutrition from fluid flow or diffusion through the vertebral endplates [42]. The metabolism in disc cells is partly anaerobic, leading to high lactic acid concentrations and low $\mathrm{pH}$ conditions [42]. Bid, cytochrome $\mathrm{C}$ and activated caspase 9 and 3 were intensively detected in herniated NP tissues [43].

Intrinsic and extrinsic pathways of apoptosis may function independently with a crosstalk between them [37]. An activation of caspase 8 is observed promoting a processing of $\mathrm{tBid}$, which subsequently stimulates Bax and Bak to engage intrinsic pathway [37]. Upregulation of proapoptotic receptors, such as DR5 by 53 (tumor suppression) may also augment extrinsic signaling [34].

Messenger RNA expressions of LC3-II/I and Beclin-1 were smaller in nucleus pulposus (NP) cells from DDD compared to cells from lumbar vertebral fracture, signaling that autophagy may develop a protective role in IVD degeneration [44]. Similar correlations in SIRT1, caspase 3, collagen II and apoptosis levels in the degenerative NP were observed in the literature [44] [45]. Human NP had similar results to those of other different tissues [46] [47]. Apoptotic pathway proteins were analyzed in Pfirrmann grade IV with higher amounts of cleaved caspases 3 and 9 in a group with low nutrition compared to a normal one [48]. Also, in a group with low nutrition (starvation) Bax protein expression was increased and Bcl-2 was attenuated, indicating a more advanced stage of degeneration [48].

If starvation was induced, autophagy was moderately increased and apoptosis of the cells maintained at a low level [49]. When it was stimulated to an extremely high level, apoptosis increased [49]. Early and moderate autophagy were beneficial to the survival of the IVD cells, while late and excessive autophagy led to death [50]. Also, it can represent a desperate attempt to mitigate the stress of the cells before apoptosis activation [49]. A regulatory process linking authophagy and apoptosis, enables a more controlled and precise response to a stress signal [49]. Autophagy and apoptosis shared the same set of cellular regulatory proteins and they could be induced by the same stimuli [51]. The interactions 


\section{Lumbar Disc Degeneration}

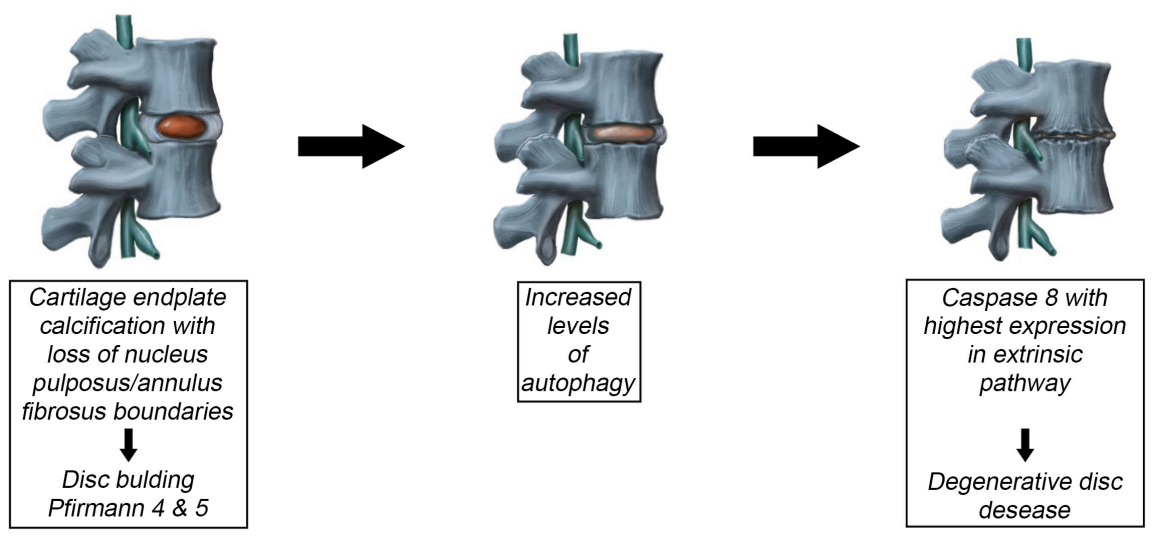

Figure 2. Mechanism for degenerative lumbar intervertebral disc.

between autophagy and apoptosis on damage or protection of the IVD cells and the homeostasis of disc matrix, remain controversial [52]. Our sample was constituted by degenerative IVD, Pfirrmann grades IV and V. It would be unethical to operate on grades I through III. Autophagy and apoptosis are key elements in determining cell fate, as well as their complex interactions and individual characteristics. It is difficult to identify a single exclusive factor that would change the balance and decide for a pro-survival or pro-death concept. It is important to clarify that the authors consider it important to expand the data and obtain more studies on the relationship between autophagy and apoptosis in LDD. This is because this topic still has many gaps to be filled and understood due to its complexity, based on further studies determining new autophagic and apoptotic markers, thus making the data in this manuscript and others clearer and the pathology easier to understand.

\section{Conclusion}

Autophagy had the greatest protein expression in human DDD. Under such conditions, autophagy and apoptosis showed a negative correlation. Caspase 8 had the highest protein expression in apoptosis, meaning a preference for the extrinsic pathway in human IVD Pfirrmann Grades IV and V IVD. It is noteworthy that due to the breadth and complexity of the topic, more studies should be carried out, where we can evaluate other caspases and autophagic processes, thus making the results of this study more consistent and applicable to clinical medicine.

\section{Acknowledgements}

The authors acknowledge financial support from AOSpine Latin America through Master's scholarship for Bruno Saciloto.

Entomology Laboratory-UCS-Prof. Wilson Sampaio de Azevedo Filho.

Our thanks to ICAP Laboratory-Karina Salgado, MD and Statistical AnalysisUCS-Prof. Luciano Selistre, MD, PhD. 


\section{Conflicts of Interest}

The authors declare no conflicts of interest regarding the publication of this paper.

\section{References}

[1] Murray, C.J.L., Vos, T., Lozano, R., et al. (2012) Disability-Adjusted Life Years (DALYs) for 291 Diseases and Injuries in 21 Regions, 1990-2010: A Systematic Analysis for the Global Burden of Disease Study 2010. The Lancet, 380, 2197-2223. https://doi.org/10.1016/S0140-6736(12)61689-4

[2] Walker, B.F. (2000) The Prevalence of Low Back Pain: A Systematic Review of the Literature from 1966 to 1998. Journal of Spinal Disorders, 13, 205-217. https://doi.org/10.1097/00002517-200006000-00003

[3] Adams, M.A. (2004) Biomechanics of Back Pain. Acupuncture in Medicine, 22, 178 188. https://doi.org/10.1136/aim.22.4.178

[4] Pfirrmann, C.W., Metzdorf, A., Zanetti, M., Hodler, J. and Boos, N. (2001) Magnetic Resonance Classification of Lumbar Intervertebral Disc Degeneration. Spine (Phila 1976), 26, 1873-1878. http://www.ncbi.nlm.nih.gov/pubmed/11568697 https://doi.org/10.1097/00007632-200109010-00011

[5] Rajasekaran, S., Babu, J.N., Arun, R., Armstrong, B.R.W., Shetty, A.P. and Murugan, S. (2004) ISSLS Prize Winner: A Study of Diffusion in Human Lumbar Discs: A Serial Magnetic Resonance Imaging Study Documenting the Influence of the Endplate on Diffusion in Normal and Degenerate Discs. Spine (Phila Pa 1976), 29, 2654 2667. http://www.ncbi.nlm.nih.gov/pubmed/15564914 https://doi.org/10.1097/01.brs.0000148014.15210.64

[6] Urban, J.P.G. and Roberts, S. (2003) Degeneration of the Intervertebral Disc. Arthritis Research \& Therapy, 5, 120-130.

http://www.ncbi.nlm.nih.gov/pubmed/12723977

https://doi.org/10.1186/ar629

[7] Park, J.-B., Lee, J.-K., Park, S.-J., Kim, K.-W. and Riew, K.D. (2005) Mitochondrial Involvement in Fas-Mediated Apoptosis of Human Lumbar Disc Cells. The Journal of Bone and Joint Surgery, 87, 1338. https://doi.org/10.2106/JBJS.D.02527

[8] Gruber, H.E., Hoelscher, G.L., Ingram, J.A., et al. (2015) Autophagy in the Degenerating Human Intervertebral Disc: In Vivo Molecular and Morphological Evidence, and Induction of Autophagy in Cultured Annulus Cells Exposed to Proinflammatory Cytokines-Implications for Disc Degeneration. Spine (Phila Pa 1976), 40, 773 782. https://doi.org/10.1097/BRS.0000000000000865

[9] Netea-Maier, R.T., Plantinga, T.S., van de Veerdonk, F.L., Smit, J.W. and Netea, M.G. (2016) Modulation of Inflammation by Autophagy: Consequences for Human Disease. Autophagy, 12, 245-260. https://doi.org/10.1080/15548627.2015.1071759

[10] Booth, L.A., Tavallai, S., Hamed, H.A., Cruickshanks, N. and Dent, P. (2014) The Role of Cell Signalling in the Crosstalk between Autophagy and Apoptosis. Cell Signaling, 26, 549-555. https://doi.org/10.1016/j.cellsig.2013.11.028

[11] Elmore, S. (2007) Apoptosis: A Review of Programmed Cell Death. Toxicologic Pathology, 35, 495-516. https://doi.org/10.1080/01926230701320337

[12] Renehan, A.G., Booth, C. and Potten, C.S. (2001) What Is Apoptosis, and Why Is It Important? BMJ, 322, 1536-1538. https://doi.org/10.1136/bmj.322.7301.1536

[13] Shpilka, T., Weidberg, H., Pietrokovski, S. and Elazar, Z. (2011) Atg8: An Autophagyrelated Biquitin-Like Protein Family. Genome Biology, 12, 226. 
https://doi.org/10.1186/gb-2011-12-7-226

[14] Zois, C.E. and Koukourakis, M.I. (2009) Radiation-Induced Autophagy in Normal and Cancer Cells: Towards Novel Cytoprotection and Radio-Sensitization Policies? Autophagy, 5, 442-450. https://doi.org/10.4161/auto.5.4.7667

[15] Bampton, E.T.W., Goemans, C.G., Niranjan, D., Mizushima, N. and Tolkovsky, A.M. (2005) The Dynamics of Autophagy Visualized in Live Cells: From Autophagosome Formation to Fusion with Endo/Lysosomes. Autophagy, 1, 23-36. https://doi.org/10.4161/auto.1.1.1495

[16] Mattiolo, P., Yuste, V.J., Boix, J. and Ribas, J. (2015) Autophagy Exacerbates Caspase Dependent Apoptotic Cell Death after Short Times of Starvation. Biochemical Pharmacology, 98, 573-586. https://doi.org/10.1016/j.bcp.2015.09.021

[17] Mukhopadhyay, S., Kumar, P., Panda, P.K., Sinha, N., Das, D.N. and Bhutia, S.K. (2014) Autophagy and Apoptosis: Where Do They Meet? Apoptosis, 19, 555-566. https://doi.org/10.1007/s10495-014-0967-2

[18] Adams, M.A. and Roughley, P.J. (2006) What Is Intervertebral Disc Degeneration, and That Causes It? Spine (Phila Pa 1976), 31, 2151-2161.

https://doi.org/10.1097/01.brs.0000231761.73859.2c

[19] He, H., Dang, Y., Dai, F., et al. (2003) Post-Translational Modifications of Three Members of the Human MAP1LC3 Family and Detection of a Novel Type of Modification for MAP1LC3B. Journal of Biological Chemistry, 278, 29278-29287. https://doi.org/10.1074/jbc.M303800200

[20] Shintani, T. and Klionsky, D.J. (2004) Autophagy in Health and Disease: A Double Edged Sword. Science (80), 306, 990-995. https://doi.org/10.1126/science.1099993

[21] Zhang, S., Yang, W., Wang, C., et al. (2016) Autophagy: A Double-Edged Sword in Intervertebral Disk Degeneration. Clinica Chimica Acta, 457, 27-35.

https://doi.org/10.1126/science.1099993

[22] Vigatto, R., Alexandre, N.M.C. and Filho, H.R.C. (2007) Development of a Brazilian Portuguese Version of the Oswestry Disability Index. Spine (Phila Pa 1976), 32, 481 486. https://doi.org/10.1097/01.brs.0000255075.11496.47

[23] Peletti-Figueiró, M., De Aguiar, I.S., Paesi, S., et al. (2017) Histological Markers of Degeneration and Regeneration of the Human Intervertebral Disk. Coluna/Columna, 16, 42-47. https://doi.org/10.1590/s1808-185120171601170833

[24] Koukourakis, M.I., Kalamida, D., Giatromanolaki, A., et al. (2015) Autophagosome Proteins LC3A, LC3B and LC3C Have Distinct Subcellular Distribution Kinetics and Expression in Cancer Cell Lines. PLoS ONE, 10, e0137675. https://doi.org/10.1371/journal.pone.0137675

[25] Wu, J., Dang, Y., Su, W., et al. (2006) Molecular Cloning and Characterization of Rat LC3A and LC3B-Two Novel Markers of Autophagosome. Biochemical and Biophysical Research Communications, 339, 437-442. https://doi.org/10.1016/j.bbrc.2005.10.211

[26] Bai, H., Inoue, J., Kawano, T. and Inazawa, J. (2012) A Transcriptional Variant of the LC3A Gene Is Involved in Autophagy and Frequently Inactivated in Human Cancers. Oncogene, 31, 4397-4408. https://doi.org/10.1038/onc.2011.613

[27] Mizushima, N. (2007) Autophagy: Process and Function. Genes \& Development, 21, 2861-2873. https://doi.org/10.1101/gad.1599207

[28] Kiriyama, Y. and Nochi, H. (2015) The Function of Autophagy in Neurodegenerative Diseases. International Journal of Molecular Sciences, 16, 26797-26812. https://doi.org/10.3390/ijms161125990 
[29] Tanida, I., Ueno, T. and Kominami, E. (2008) LC3 and Autophagy. Methods in Molecular Biology (Clifton, N.J.), 445, 77-88. https://doi.org/10.1007/978-1-59745-157-4_4

[30] Li, S., Hua, W., Wang, K., et al. (2018) Autophagy Attenuates Compression-Induced Apoptosis of Human Nucleus Pulposus Cells via MEK/ERK/NRF1/Atg7 Signaling Pathways during Intervertebral Disc Degeneration. Experimental Cell Research, 370, 87-97. https://doi.org/10.1016/j.yexcr.2018.06.012

[31] Ma, K., Shao, Z., Yang, S., et al. (2013) Autophagy Is Activated in CompressionInduced Cell Degeneration and Is Mediated by Reactive Oxygen Species in Nucleus Pulposus Cells Exposed to Compression. Osteoarthritis and Cartilage, 21, 2030 2038. https://doi.org/10.1016/j.joca.2013.10.002

[32] Chen, J., Ni, B., Zheng, X., Li, B.B., Jiang, S. and Jiang, L. (2015) Hypoxia Facilitates the Survival of Nucleus Pulposus Cells in Serum Deprivation by Down-Regulating Excessive Autophagy through Restricting ROS Generation. The International Journal of Biochemistry \& Cell Biology, 59, 10.

https://doi.org/10.1016/j.biocel.2014.11.009

[33] Klionsky, D.J., Abdelmohsen, K., Abe, A., et al. (2016) Guidelines for the Use and Interpretation of Assays for Monitoring Autophagy (3rd Edition). Autophagy, 12, 1-222. https://doi.org/10.1080/15548627.2015.1100356

[34] Zhang, F., Zhao, X., Shen, H. and Zhang, C. (2016) Molecular Mechanisms of Cell Death in Intervertebral Disc Degeneration (Review). International Journal of Molecular Medicine, 37, 1439-1448. https://doi.org/10.3892/ijmm.2016.2573

[35] Ghobrial, I.M., Witzig, T.E. and Adjei, A. (2005) Targeting Apoptosis Pathways in Cancer Therapy. CA: A Cancer Journal for Clinicians, 55, 178-194. https://doi.org/10.3322/canjclin.55.3.178

[36] Stanzer, S., Janesch, B., Resel, M., Augustin, T., Samonigg, H. and Bauernhofer, T. (2010) The Role of Activation-Induced Cell Death in the Higher Onset of Spontaneous Apoptosis of NK Cell Subsets in Patients with Metastatic Epithelial Cancer. Cellular Immunology, 261, 99-104. https://doi.org/10.1016/j.cellimm.2009.11.006

[37] Ashkenazi, A. (2008) Directing Cancer Cells to Self-Destruct with Pro-Apoptotic Receptor Agonists. Nature Reviews Drug Discovery, 7, 1001-1012. https://doi.org/10.1038/nrd2637

[38] Zhang, C. and Zhang, F. (2015) The Multifunctions of WD40 Proteins in Genome Integrity and Cell Cycle Progression. Journal of Genomics, 3, 40-50. https://doi.org/10.7150/jgen.11015

[39] Gruber, H.E., Ingram, J.A., Norton, H.J. and Hanley, E.N. (2007) Senescence in Cells of the Aging and Degenerating Intervertebral Disc. Spine (Phila Pa 1976), 32, 321-327. https://doi.org/10.1097/01.brs.0000253960.57051.de

[40] Zhao, L., Tian, B., Xu, Q., Zhang, C., Zhang, L. and Fang, H. (2019) Extensive Mechanical Tension Promotes Annulus Fibrosus Cell Senescence through Suppressing Cellular Autophagy. Bioscience Reports, 39, BSR20190163. https://doi.org/10.1042/BSR20190163

[41] Pattingre, S., Espert, L., Biard-Piechaczyk, M. and Codogno, P. (2008) Regulation of Macroautophagy by mTOR and Beclin 1 Complexes. Biochimie, 90, 313-323. https://doi.org/10.1016/j.biochi.2007.08.014

[42] Sakai, D. and Grad, S. (2015) Advancing the Cellular and Molecular Therapy for Intervertebral Disc Disease. Advanced Drug Delivery Reviews, 84, 159-171. https://doi.org/10.1016/j.addr.2014.06.009

[43] Erwin, W.M., Islam, D., Davies-Inman, R., Fehlings, M.G. and Tsui, F.W. (2012) 
Notochordal Cells Protect Nucleus Pulposus Cells from Apoptosis: Implications for the Mechanisms of Intervertebral Disc Degeneration. The Spine Journal, 12, 1-15. https://doi.org/10.1016/j.spinee.2012.08.127

[44] Jiang, W., Zhang, X.X., Hao, J., et al. (2014) SIRT1 Protects against Apoptosis by Promoting Autophagy in Degenerative Human Disc Nucleus Pulposus Cells. Scientific Reports, 4, 7456. https://doi.org/10.1038/srep07456

[45] Wang, D., Hu, Z., Hao, J., et al. (2013) SIRT1 Inhibits Apoptosis of Degenerative Human Disc Nucleus Pulposus Cells through Activation of Akt Pathway. Age (Omaha), 35, 1741-1753. https://doi.org/10.1007/s11357-012-9474-y

[46] Saunders, L.R. and Verdin, E. (2007) Sirtuins: Critical Regulators at the Crossroads between Cancer and Aging. Oncogene, 26, 5489-5504.

https://doi.org/10.1038/sj.onc.1210616

[47] Caramés, B., Taniguchi, N., Otsuki, S., Blanco, F.J. and Lotz, M. (2010) Autophagy Is a Protective Mechanism in Normal Cartilage, and Its Aging-Related Loss Is Linked with Cell Death and Osteoarthritis. Arthritis \& Rheumatology, 62, 791-801. https://doi.org/10.1002/art.27305

[48] Miyazaki, S., Kakutani, K., Yurube, T., et al. (2015) Recombinant Human SIRT1 Protects against Nutrient Deprivation-Induced Mitochondrial Apoptosis through Autophagy Induction in Human Intervertebral Disc Nucleus Pulposus Cells. Arthritis Research \& Therapy, 17, 253. https://doi.org/10.1186/s13075-015-0763-6

[49] Rubinstein, A.D. and Kimchi, A. (2012) Life in the Balance-A Mechanistic View of the Crosstalk between Autophagy and Apoptosis. Journal of Cell Science, 125, 52595268. https://doi.org/10.1242/jcs.115865

[50] Ni, B.-B., Li, B., Yang, Y.-H., et al. (2014) The Effect of Transforming Growth Factor betal on the Crosstalk between Autophagy and Apoptosis in the Annulus Fibrosus Cells under Serum Deprivation. Cytokine, 70, 87-96. https://doi.org/10.1016/j.cyto.2014.07.249

[51] Maiuri, M.C., Zalckvar, E., Kimchi, A. and Kroemer, G. (2007) Self-Eating and Self-Killing: Crosstalk between Autophagy and Apoptosis. Nature Reviews Molecular Cell Biology, 8, 741-752. https://doi.org/10.1038/nrm2239

[52] Chen, J.-W., Ni, B.-B., Li, B., et al. (2014) The Responses of Autophagy and Apoptosis to Oxidative Stress in Nucleus Pulposus Cells: Implications for Disc Degeneration. Cellular Physiology and Biochemistry, 34, 1175-1189.

https://doi.org/10.1159/000366330 


\section{Abbreviations and Acronyms}

IVD: intervertebral disc

DDD: degenerative disc disease

LBP: low back pain

IDD: intervertebral disc degeneration

NP: nucleus pulposus

ECM: extracellular matrix

ATG: autophagy related genes

LC3: microtubule-associated protein 1A/1B light chain 3B

MRI: magnetic resonance imaging

AU: arbitrary units

GLM: generalizes linear model

APAF1: Apoptotic protease activating factor 1

TNFR1: tumor necrosis factor receptor 1

Fas: apoptosis antigen 1

DISC: death-inducing signaling complex

m-TOR: mammalian target of rapamycin

TOR: target rapamycin

PKA: Ras-c-AMP-dependent protein Kinase A

SIRT1: sirtuin 1

AF: annulus fibrosus 